\title{
Refraction as a means of predicting squint or amblyopia in preschool siblings of children known to have these defects
}

\author{
R. M. INGRAM AND C. WALKER \\ From the Kettering and District General Hospital, Kettering
}

SUMMARY 215 preschool siblings of children presenting with squint/amblyopia were screened by refraction after cycloplegia. The presence of +2.00 or more $D$ of spherical hypermetropia in both eyes, or +1.00 or more $D$ sphere or cylinder of anisometropia was significantly associated $(P=0.0779 \%)$ with that child being identified $2+$ years later as having either squint or amblyopia or both. Astigmatism of +1.50 or more $D$ in either eye was significantly associated with anisometropia $(P=0.0000013 \%)$. If bilateral hypermetropia of +2.00 or more DS and/or +1.50 or more $\mathrm{D}$ of astigmatism in either eye had been taken as criteria for abnormality (ignoring anisometropia), there was a more significant association $(P=0.0025 \%)$ between refraction and squint/amblyopia in these siblings. Such a child had 4 times more chance of having a visual defect than one who had no error of refraction when screened. These findings suggest that an environmental factor such as blurred vision may be relatively more important as a cause of squint/amblyopia than a genetically determined neurological abnormality.

Thomson (1924) and Chavasse (1932) suggested preventive treatment for squint without specifying which children required it. Bruckner, as reported and confirmed by Seba (1970), probably tried to predict which children were going to squint but did not refer this to a method of prevention. His test was, to say the least, vague, but we think that he was possibly identifying children with abnormal refractions. Kramar (1973), however, looked specifically for a test that might enable us to predict, and she suggested that refraction might offer a better chance of doing this than examination of other physical parameters. This offered the opportunity of a genuinely new approach to squint and amblyopia because it happened directly to lead to treatment that could possibly be preventive, that is, that suggested by Thomson (1924) and Chavasse (1932). Ingram (1977) enlarged on this by pointing out the advantages that an objective test had over new or improved subjective tests, particularly with a view to identifying the 'non-squinting' amblyopes as well as those who were going to squint.

Refraction without cycloplegia has been used before to screen schoolchildren for defective vision (Tyser and Letchworth, 1949; Hirsch, 1950; Jevons,

Address for reprints: Dr R. M. Ingram, Kettering and District General Hospital, Rothwell Road, Kettering, Northamptonshire NN16 8UZ
1954). It has also been recommended, after cycloplegia, as part of a full ocular examination of children at birth (Seba, 1974), aged 3 to 6 months (Winstanley, 1966) and aged 3+ years (Abeloos, 1970; Litvinova et al., 1964). So far as we are aware, nobody has yet explored the possibility of using cycloplegic refraction actually to predict which children will be identified later as having squint and/ or amblyopia.

The obvious way to test Kramar's (1973) suggestion would be to try it on a group of children unusually liable to have squint and/or amblyopia, for example, preschool siblings of those who actually present with these conditions. We report a follow-up study of 215 siblings reviewed $2+$ years after they were first screened by retinoscopy following cycloplegia with cyclopentolate (Cyclogyl $1 \%$ ).

A future publication (Ingram et al., 1979) reports the findings of follow-up of 186 children seen in a pilot study designed to find out if it would be practical to screen routinely 1-year-old children by refraction. Both samples have been assessed by the same criteria to enable comparison to be made.

\section{Sample of children}

215 preschool siblings of children who presented with squint and/or amblyopia were screened during 
a 3-year period 1971-74. One of us (R. M. I.), who recorded the findings of these children as they were screened, is conscious of the fact that the 'recordkeeping' was not as diligent as it might have been. Therefore we cannot claim that the 215 children reported here were a truly consecutive series, because: (1) Some preschool siblings were not brought for screening. (2) The records of the findings from some siblings were mislaid. We think that there were not more than 10 of these and that all were found to have a 'normal' refraction when screened. We do not think that these deficiencies alter our conclusions. Unfortunately, however, we cannot make any observations on what appears to be a high incidence of refractive errors in siblings of children who present with squint and/or amblyopia.

\section{Methods}

Retinoscopy of each child was performed after cycloplegia with cyclopentolate (Cyclogyl 1\%) drops. The refraction in 2 meridia of each eye was recorded on the principles suggested by Ingram (1977). All the refractions were performed by the same person (R. M. I.).

At the time of screening we considered that +2.00 DS of hypermetropia in both eyes was a significant amount of hypermetropia, and that +1.00 or more DS or +1.00 or more D cyl. difference between the two eyes was a significant amount of anisometropia, and that children with such refractions should be regarded as 'abnormal'.

A number of children were periodically reviewed, and 35 of them were treated with spectacles at some time before their final assessment.

\section{Final assessment}

An attempt was made to review all the children $2+$ years after their initial screening. We have chosen 3 criteria on which to assess whether an individual child's vision was normal or abnormal, because they could also be applied to the simultaneous assessment and reporting of the pilot study of children screened at the age of 1 year and reviewed at the age of $3 \frac{1}{2}$ years (Ingram et al., 1979): (1) Esotropia or exotropia, detectable by the cover test. (2) Visual acuity of $<6 / 12$ in either eye, measured only with the Linear Sheridan-Gardiner or Snellen tests. (3) The difference between the corrected visual acuity of the 2 eyes of $>1$ line, again measured only with the Linear Sheridan-Gardiner or Snellen tests.

In some children we found difficulty in interpreting the 4 dioptre prism test for microtropia, and we have not therefore included this as a criterion of abnormality. However, where we felt sure that there was a microtropia we have recorded it but made no further observations.

We accept that treatment of some of the children before a visual abnormality was detected has complicated the final assessment, particularly in relation to the recording of visual acuity. If the visual acuity was $6 / 12$ or better with a spectacle correction, we have counted the acuity as 'normal' unless there was $>1$ line of difference between the 2 eyes. Manifest squint with or without spectacles has been counted as 'abnormal'.

Thirty-one children did not attend again for reassessment, and 22 others had apparently moved from our area. Thus, 162 children have been reassessed. They were divided into 2 groups according to whether they did or did not have an 'abnormal' refraction when they were screened. We have not published full details of the refractions and vision of all the individual children, but we would be happy to supply photocopies of them to interested inquirers.

\section{Summary of findings}

The visual findings from these children can be summarised and statistically analysed in terms of whether detection of an 'abnormal' refraction at the time of screening was significantly associated with a child being eventually found to have normal or abnormal vision. Thus, detection of bilateral spherical hypermetropia and/or anisometropia was significantly associated with the future detection of squint and/or amblyopia (Table 1).

Refractions other than bilateral hypermetropia and/or anisometropia could be considered in retrospect as being abnormal. For example, if $+1 \cdot 50$ D of astigmatism in either eye had also been regarded as 'abnormal', even when there was no significant hypermetropia or anisometropia, such a refraction would have been significantly associated with the later detection of squint and/or amblyopia (Table 2).

If anisometropia had been ignored, and the criteria for 'abnormality' taken as hypermetropia of +2.00 or more $D$ in both eyes and/or +1.50 or

Table 1

\begin{tabular}{lllc}
\hline & Normal vision & Squint/amblyopia & Total \\
\hline Normal refraction & 99 & 14 & 113 \\
Abnormal refraction & 31 & 18 & 49 \\
Total & 130 & 32 & 162 \\
\hline
\end{tabular}

$x^{2}=11 \cdot 29 . \quad P=0.0779 \%$ 
Table 2

\begin{tabular}{llll}
\hline & Normal vision & Squint/amblyopia & Total \\
\hline Normal refraction & 94 & 11 & 105 \\
Abnormal refraction & 36 & 21 & 57 \\
Total & 130 & 32 & 162 \\
\hline
\end{tabular}

$\chi^{2}=14.58 . \quad P=0.0134 \%$

Table 3

\begin{tabular}{llllc}
\hline & Normal vision & Squint/amblyopia & Total \\
\cline { 1 - 1 } \cline { 5 - 5 } Normal refraction & 98 & 11 & 109 \\
Abnormal refraction & 32 & 21 & 53 \\
Total & 130 & 32 & 162 \\
\hline
\end{tabular}

$\chi^{2}=17.80 . \quad P=0.0025 \%$

more $\mathbf{D}$ astigmatism in either eye, such a refraction would have been slightly more significantly associated with the later detection of squint and/or amblyopia (Table 3).

OBSERVATIONS ON THE POSSIBLE CONSEQUENCES OF OUR TREATING 12 OF THE CHILDREN We can only guess at the effects of the treatment we gave to some of these children, but it is reasonable to suppose that if 8 children had not been identified and treated they would have been detected later by the school screening programme. All 8 had +2.00 D or more astigmatism in 1 or both eyes at the age of 5 years or later. If they had not been screened, it is reasonable to suppose that we would have identified 29 out of the 40 children with a visual abnormality, that is, $72 \%$. It is possible that 4 others would also have presented with a visual defect if they had not also been screened and treated.

\section{ANISOMETROPIA AND ASTIGMATISM}

We also record for future reference the association in this sample of preschool siblings between the presence of anisometropia on the one hand and astigmatism of +1.50 or more $D$ in either or both eyes on the other hand (Tables 4 and 5).

\section{Discussion}

PREDICTION BY REFRACTION OF SIBLINGS In this series of preschool siblings of children presenting with squint and/or amblyopia there is a statistically significant relationship (Table $1, \mathbf{P}=$ $0.0779 \%$ ) between the presence of what we have regarded as significant (Ingram, 1977) amounts of hypermetropia and/or anisometropia and the future identification of squint or defective visual acuity in that sibling. However, only $56 \%$ (Table 1 ) of those who eventually had a visual defect were predicted on the basis of these refractions. This compares with $72 \pm 3 \%$ of children who were found to have hypermetropia and/or anisometropia at the time they presented with squint and/or amblyopia (Ingram, 1977) and a prediction rate of $73 \%$ of children screened in our pilot study of 1-year-olds (Ingram et al., 1979).

Since we started this particular investigation, the entity of meridional amblyopia has been identified (Mitchell et al., 1973) and accepted as a form of stimulus deprivation amblyopia (Noorden, 1974). A significant association between astigmatism of $+1.50 \mathrm{D}$ or more in either or both eyes and what we have regarded as significant amounts of anisometropia was noted in this sample of children (Table 4, $P=0.0000013 \%$ ) among 1-year-old children (Ingram, 1979) and in children at the time they present with a visual problem (Ingram, unpublished). If we had taken $+1.50 \mathrm{D}$ or more astigmatism in either eye, in addition to bilateral hypermetropia and/or anisometropia, and regarded all 3 as 'abnormal', the significance of any 1 or more of these refractions being associated with the future identification of squint/amblyopia increases (Table 2, $\mathrm{P}=0.0134 \%$ ). If, however, we had ignored anisometropia and just selected bilateral hypermetropia of +2.00 or more DS and/or astigmatism of +1.50 or more $D$ in either eye as abnormal criteria, we would have had an even higher statistical association (Table $3, P=0.0025 \%$ ), and we would have predicted abnormal vision in $66 \%$ of those

Table 4 Anisometropia and astigmatism (astigmatism in either or both eyes)

\begin{tabular}{lccc}
\hline & No Aniso. & Aniso. & Total \\
\hline 0 to +1.25 D cyl. & 179 & 7 & 186 \\
+1.50 or more D cyl. & 16 & 13 & 29 \\
Total & 195 & 20 & 215 \\
\hline
\end{tabular}

$P=0.0000013 \%$

Table 5 Anisometropia and astigmatism (astigmatism in either or both eyes)

\begin{tabular}{lccc}
\hline & No Aniso. & Aniso. & Total \\
\hline 0 to +0.75 D cyl. & 168 & 2 & 170 \\
+1.00 or more D cyl. & 27 & 18 & 45 \\
Total & 195 & 20 & 215 \\
\hline $\mathbf{P}=0$ & & &
\end{tabular}


children eventually found to have a visual defect.

In some respects it is unfortunate that we treated 35 of these children with spectacles. We believe that if 8 of them had not been treated they would eventually have been found to have defective vision, and we would have predicted $72 \%$ of those who should eventually present with an abnormality. There is therefore strong circumstantial evidence to support Kramar's (1973) suggestion.

Absence of hypermetropia or astigmatism (or anisometropia) at the time a preschool sibling is seen at the age of 1 year or later does not preclude future identification of squint and/or amblyopia: such a child had a $10 \%$ chance of later being found to have squint and/or amblyopia. On the other hand, if that child had hypermetropia or astigmatism, he/she had a 2 in 5 chance of being found later to have a visual defect, and this is 4 times higher than it would have been if no abnormality of refraction had been found.

AETIOLOGY OF SQUINT AND/OR AMBLYOPIA It seems that the cause of squint and/or amblyopia could be either an environmental factor such as blurred vision affecting a system of neuronal connections between retina and cortex that is developing during the first few months of life (see, for example, Ikeda and Tremain, 1978; Blakemore and Eggers, in press) or a genetically determined inborn neurological abnormality, as suggested by Wiesel and Hubel (1974). Alternatively, there could be both a genetic and an environmental factor (see Whitteridge, 1977) acting separately or coincidentally. The species of experimental animal may be important, because in the kitten, whose eye is 'immature' at birth, the process of development may be relatively more important and therefore the neuronal connections may be more easily distorted by environmental factors than is the case in higher mammals, for example, the lamb. Recent work shows that vision develops rapidly during the first 3 months of the human infant's life, which suggests that the neuronal connections may not be as well developed as in the lamb (Atkinson et al., 1977).

The presence of identical squint in uniovular twins has been cited in favour of the genetic basis of squint (Whitteridge, 1977). In this sample, 1 such pair of twins developed squint in the absence of any refractive error when they were screened. Nevertheless, uniovular twins often have identical refractions (Sorsby and Benjamin, 1973; Weekers et al., 1956), although this is not inevitable (Kvapilikova, 1970), and there is other evidence that refraction is inherited (Waardenburg, 1963; Sorsby et al., 1966). This pair of twins were 2 years old when screened, and the absence of a refractive error at this age does not preclude the possibility that they had an abnormal refraction when they were younger.

Preschool siblings of children known to have squint or amblyopia might be expected to have a significant risk of having a genetically determined neurological abnormality. Nevertheless, in this sample there is a highly significant association between a refractive error and the eventual identification of a visual defect. This is compatible with other observations, as follows:

(1) There was a significant association between refractive errors and visual defect $(P<0.01)$ among the subjects in the 20 families specifically selected by Kramar (1973) because of the distribution of squint/ amblyopia within them. (2) Among children presenting before the age of 2 years with squint/amblyopia the association of a refractive error was more significant than the reported incidence of a family history (Ingram, 1973). (3) In a sample of children of all ages presenting with possible visual problems the association of a refractive error with squint/ amblyopia was itself significantly higher $(\mathrm{P}<0.05)$ than the (already significant) incidence of a family history (Ingram, 1977).

Taken together, these observations suggest that, in man, an environmental factor such as blurred vision caused by an uncorrected refractive error may be a more important factor causing squint and/or amblyopia than an inborn neurological lesion. If this is so, attention could be directed towards the search for refractive errors of sufficient magnitude to cause blurred vision during the sensitive period. If it was ever possible to demonstrate successful prevention of squint and/or amblyopia by creating clear vision throughout this period, we would have gone some way towards deciding the relative importance of the genetic and developmental theories.

We thank Dr A. Barr for the statistical analyses and Mrs L. Neale for secretarial help.

The work was supported by a grant from the research funds of the Oxford Regional Health Authority.

\section{References}

Abeloos, E. (1970). Ametropie et inspection medicale scolaire. Bulletin de la Société Belge d'Ophtalmologie, 154, 443-448.

Atkinson, J., Braddick, O., and Moar, K. (1977). Development of contrast sensitivity over the first three months of life in the human infant. Vision Research, 17, 1037-1044.

Blakemore, C., and Eggers, H. (In press). Animal models for human visual development. In Proceedings of $a$ Dedicatory Symposium for the College of Optometry. University of Houston.

Chavasse, B. (1932). In Symposium of non-paralytic squint. Transactions of the Ophthalmological Societies of the United Kingdom, 52, 348-352. 
Hirsch, M. J. (1950). A skiascopic procedure for visual screening surveys. American Journal of Optometry, 27, 587-591.

Ikeda, H., and Tremaine, K. E. (1978). Amblyopia resulting from penalisation. Neurophysiological studies of kittens reared with atropinisation of one or both eyes. British Journal of Ophthalmology, 62, 21-28.

Ingram, R. M. (1973). Prediction of strabismus. Family history and refractive errors in children under the age of two years. British Orthoptic Journal, 30, 74-80.

Ingram, R. M. (1977). Refraction as a basis for screening children for squint and amblyopia. British Journal of Ophthalmology, 61, 8-15.

Ingram, R. M. (1979). Refractions of 1-year-old children after atropine cycloplegia. British Journal of Ophthalmology, 63 (in press).

Ingram, R. M., Traynar, M. J., Walker, C., and Wilson, J. (1979). Screening for refractive errors at age 1 year: a pilot study. British Journal of Ophthalmology, 63, 243-250.

Jevons, N. A. (1954). Ascertainment of visual defects in young children. Medical Officer, 92, 228.

Kramar, P. O. (1973). The possibility of predicting the appearance of strabismus. British Orthoptic Journal, 30, 66-73.

Kvapilikova, K. (1970). Refractive errors in twins. Ceskoslovenská Oftalmologie, 26, 282-287.

Litvinova, M. P., Volokitenko, A. E., and Pikalova, L. D. (1964). Refraction and binocular vision in children under school age. Oftalmologicheskii Zhurnal, 2, 87-91.

Mitchell, D. E., Freeman, R. D., Millodot, M., and Haegerstrom, G. (1973). Meridional amblyopia: evidence for modification of the human visual system by early visual experience. Vision Research, 13, 535-558.
Noorden, G. K. von (1974). Factors involved in the production of amblyopia. British Journal of Ophthalmology, 58, 158164.

Seba, J. (1970). On Bruckner's method of screening children. Ophthalmologica, 160, 421-429.

Seba, J. (1974). Ophthalmological findings in newborn children. Ceskoslovenská Oftalmologie, 30, 42-47.

Sorsby, A., and Benjamin, B. (1973). Mode of inheritance of errors of refraction. Journal of Medical Genetics, 10, 161164.

Sorsby, A., Leary, G. A., and Fraser, G. R. (1966). Family studies in ocular refraction and its components. Journal of Medical Genetics, 3, 269-273.

Thomson, W. E. (1924). In symposium on squint. Transactions of the Ophthalmological Societies of the United Kingdom, 44, 238-252.

Tyser, P. A., and Letchworth, T. W. (1949). A study in visual defects in young children. British Medical Journal, 2, 1022-1023.

Waardenburg, P. J. (1963). Genetics and Ophthalmology, pp. 1214-1285. Blackwell Scientific Publications: Oxford.

Weekers, R., Moureau, P., Harcourt, J., and Andre, A. (1956). Contribution à l'étiologie du strabisme concomitant et de l'amblyopie per l'étude de jumeaux uni- et bi-vitellins. Ophthalmologica, 132, 209-229.

Whitteridge, D. (1977). The cortical contribution to binocular vision. Transactions of the Ophthalmological Societies of the United Kingdom, 97, 39-47.

Wiesel, T. N., and Hubel, D. H. (1974). Ordered arrangement of orientation columns in monkeys lacking visual experience. Journal of Comparative Neurology, 158, 307-318.

Winstanley, R. A. (1966). Amblyopia may be preventable. Sight-Saving Review, 36, 212-215. 